\title{
Values of sustainable development as motives for sharing
}

\author{
Olga Saginova ${ }^{1, *}$, Ekaterina Tsenina $^{1}$, Yuri Saginov ${ }^{1}$, and Dmitry Zavyalov ${ }^{1}$ \\ ${ }^{1}$ Plekhanov Russian University of Economics, Entrepreneurship and Logistics Department, \\ Stremyanny lane 36, 117997 Moscow, Russia
}

\begin{abstract}
The distributed use economy is using digital platforms and partially overlaps with sharing, collaborative consumption, and on-demand systems, providing various models of peer-to-peer exchanges of tangible and intangible assets. Distributed use and sharing are believed to demonstrate the triple bottom-line of the sustainable development with focus on environmental, economic and social issues. The behaviour of the distributed use economy users is determined by several main motives: getting pleasure from and enjoying new technologies, realizing users' views on reasonable consumption, strengthening one's reputation among members of the community, and obtaining economic benefits. The article presents the results of research of distributed use economy users and the relation of their motives to the values of sustainable development. Online survey and deliberative research sessions revealed the importance of sustainable development values for the young active consumers.
\end{abstract}

\section{Introduction}

The changes that have taken place in the global economy over the past 20 years have transformed the consumer markets and consumer behaviour. The development of information and communication technologies and the spread of innovations in this area have initiated the process of digital transformation of the economy and society, turning information into an important and valuable resource. New technologies have changed the way of life, providing a greater choice of digital products, more complete information, additional distribution channels, ease of transactions for consumers. There are changes in the structure of consumption, it is becoming more diverse, individualized, situational. The attitude of consumers to the goals and process of consumption is changing, and the importance of social and environmental motives is growing.

Previously, researchers attributed consumers' indifference to consumer ethics and sustainable consumption to the existing economic and institutional constraints, which made it easier for the consumers to stick to the pragmatic approach of consumerism [15]. The emergence and development of the concept and models of sharing economy supported by modern technological solutions affect the motives of consumer behaviour. The sharing economy is growing exponentially: according to PricewaterhouseCoopers, revenue for

\footnotetext{
* Corresponding author: saginova.ov@rea.ru
} 
companies in the distributed use economy will reach $\$ 335$ billion by 2025 [22]. Due to the increasing importance of the sharing economy and its impact on the economic development of individual countries and entire regions, it is important to understand the motivations of consumers using different distributed use models and the relation of these motives to consumers' value sets.

Research literature presents the benefits of using sharing relating them to the values of sustainable development, since initially sharing was aimed at offering access to the unused or underutilized assets and resources [2, 15, 21], it is believed that sharing economy motivates more responsible and sustainable consumption. Digital platforms that enable peer-to-peer asset exchanges provide consumers not only with access to assets that they cannot purchase, but also with an opportunity to earn additional income [6]. Another positive feature of sharing is the expansion and activation of social contacts and interaction, which not only meets the need of people to communicate, but can also socially activate them, turning them into conscious, active citizens [28]. This paper is analysing the main drivers of using sharing services by young active consumers and the relation of these motives to consumers' values. The results of online survey and two deliberative research sessions are compared to the existing body of empirical data in recent research publication.

\section{Distributed use and sharing economy}

In the research literature, there are several terms that define the concept of exchanging or jointly using some assets or resources: collaborative consumption and collaborative economy, sharing consumption and sharing economy, peer economy, gig economy, ondemand economy, second-hand economy, distributed economy, etc. [14]. Analysis by Dredge and Gyimóthy [7] identified 17 different terms that describe these related concepts. It is important to differentiate the concepts and clearly define the relations between the terms used. We suggest to use the concept of distributed use economy as the most general term for economic relationships between individuals and/or organizations regarding the provision of access, transfer of ownership, or sharing of assets and resources mediated by digital platforms and information technologies, and allowing for the rational use and distribution of investments, resources, human capital, and other assets to support harmonious and sustainable development [25].

The term "distributed economy" was used by Johansson [16] in relation to regionally distributed assets, as well as the distribution of the value creation process not only between large manufacturing enterprises, but also between small and medium-sized businesses and self-employed citizens. The term "distributed economy" is used mainly to describe the trend towards decentralization of production and public life [12] and managing regional production complexes [17]. Distributed use economy includes sharing, but while sharing is a peer-to-peer exchange (P2P), distributed use economy can also include transactions between businesses (B2B) and between organisation and consumers (B2C). Distributed use economy includes second-hand economy not only in terms of transferring used clothes or toys to those in need, but also providing access or transferring property rights for tools and instruments, equipment and other assets once they are no longer needed by the owner. The differences between sharing, distributed use economy and other related concepts are shown in table 1 . 
Table 1. Distributed use economy and other related concepts.

\begin{tabular}{|c|c|c|}
\hline Characteristics & Distributed use economy & Related concepts \\
\hline Ownership rights & $\begin{array}{c}\text { Can be transferred during } \\
\text { transactions alongside with } \\
\text { provision of access }\end{array}$ & $\begin{array}{c}\text { Sharing economy only provides } \\
\text { access to assets } \\
\text { Second-hand economy transfers } \\
\text { the ownership rights }\end{array}$ \\
\hline Level of exchange & P2P, B2B, B2C & Sharing economy - P2P \\
\hline Assets exchanged & $\begin{array}{c}\text { Both underutilised and specially } \\
\text { produced/acquired assets }\end{array}$ & $\begin{array}{c}\text { On-demand economy }- \text { only } \\
\text { underutilised assets }\end{array}$ \\
\hline $\begin{array}{c}\text { Mediation of digital } \\
\text { platforms }\end{array}$ & $\begin{array}{c}\text { Used either for information } \\
\text { transfer or transaction or both }\end{array}$ & $\begin{array}{c}\text { Can be used, but is not } \\
\text { compulsory }\end{array}$ \\
\hline
\end{tabular}

The objective of this paper being finding out the motives of young active consumers for distributed use economy, we did not differentiate between sharing, second-hand and ondemand economy segments, and the concept of distributed use economy made it possible.

\section{Motives for sharing}

In the research literature, one can find empirical evidence of certain drivers of distributed use in the models of car sharing [1], housing rental [28], and exchange of tangible assets [19]. Many authors believe the key driver of distributed use is maximizing personal utility $[2,15]$. Personal utility includes such indicators as cost, consumer value, and convenience. All of them relate to economic benefits of distributed use economy. Among the studied motives for sharing, enjoyment of the process and a sense of novelty have been identified. Innovators by nature tend to experience pleasure from the use of new technologies and distribution channels with the mediation of digital platforms. This motivation can also be associated with an external factor such as maintaining one's reputation as an innovator and sophisticated user among members of one's community. This last motive can already be attributed to the social benefits of sharing [28]. Social benefits can also include a sense of belonging to a community or network [12].

Basing on the data available in the research articles, three groups of motives were identified: economic, ecological, and social. Economic motivation includes such factors as access being more important than ownership, saving money and time, ease of use. Social motivation includes user's reputation, recognition, and respect by the community. Ecological motives mean compliance with the principles of sustainable development, support for reasonable consumption, saving world's resources. We added a hedonistic motivation showing the feeling of enjoyment, and a sense of novelty.

\subsection{Online survey methodology}

Empirical data on the distributed use motivation was collected by an online survey of young active consumers [26]. 184 valid questionnaires were collected. The questionnaire included 2 main sections: the first section identified the attitude of respondents to the distributed use economy and frequency of using these services, as well as the desire and intention to use them in the future. In the second section respondents were asked to fill in their agreement or disagreement with the statements about distributed use economy. The statements were grouped into four parts, one for each of the established motives types. The level of agreement with each statement was estimated using a 7-point Likert scale from "completely agree" to "completely disagree". The integral assessment of each motivation 
was the sum of points for all responses for each type of motivation. The more points the respondent scored in the survey, the more pronounced the motivation was.

Since models describing the motivation for distributed use economy are based on integral estimates, questions about motivations were tested for reliability by calculating the Cronbach alpha. The results are presented in table 2.

Table 2. Cronbach alpha meanings.

\begin{tabular}{|c|c|}
\hline Motivations & Cronbach alpha $\mathrm{n}=184$ \\
\hline Economic motivation & 0,839 \\
\hline Ecological motivation & 0,903 \\
\hline Reputation motivation & 0,937 \\
\hline Enjoyment motivation & 0,891 \\
\hline
\end{tabular}

All the results obtained are more than 0.7 , therefore, there is a good internal consistency of the statement groups in the questionnaire.

\subsection{Online survey results and discussion}

Fuzzy sets were used to model the motivations for sharing consumption. The use of fuzzy logic for analysing survey results allowed to work with fuzzy estimates ("more important to me", "I agree rather than disagree", "less important to me"). To build models, the total range of scores (4 questions times 7 points maximum) was divided into parts, then the number of responses in each part of the questionnaire was calculated, as well as the proportion of responses and their accumulated scores. The accumulated share of responses sets the membership function of a fuzzy set that expresses the concept of the "type of motivation for distributed use economy" in terms of a point-based assessment of the motivation significance. These pairs of numbers can be joined by a curve using Microsoft Office Excel.

Fig. 1 shows models of motivation for distributed use economy in the form of fuzzy sets. In our case, the fuzzy set is characterized by a sigmoid membership function. 


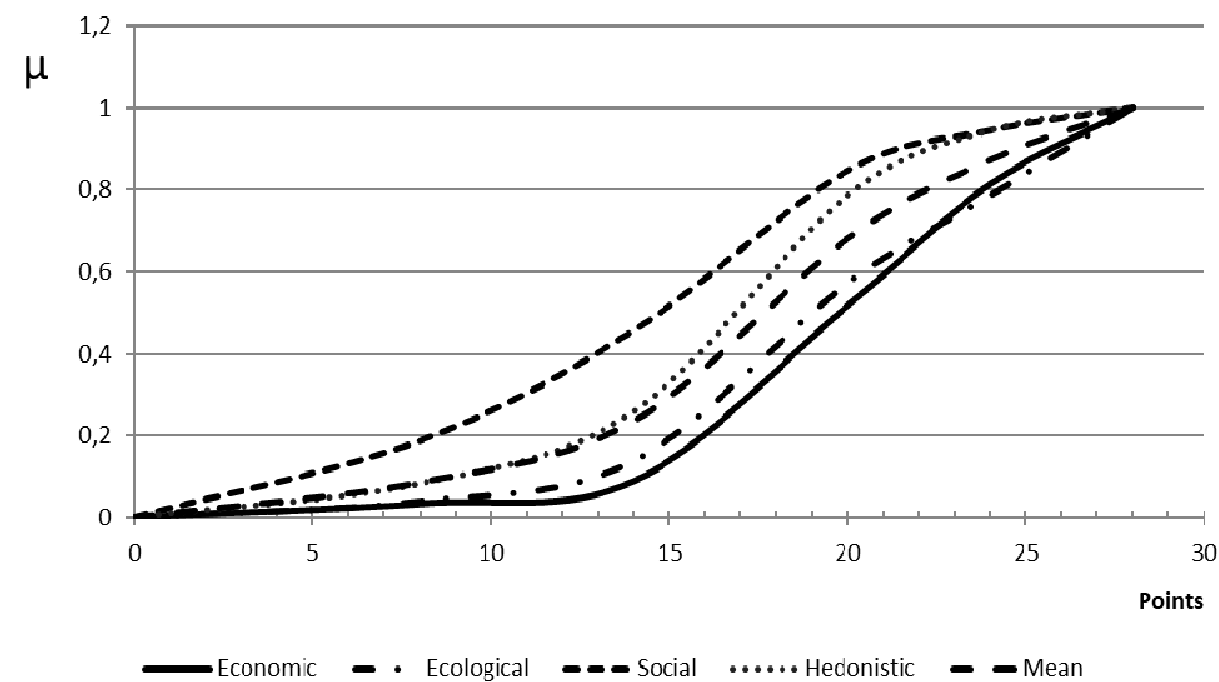

Fig. 1. Models of motivation for distributed use economy.

We can conclude that the strongest motivation of respondents is economic - the desire to save money or time making the transaction easy and convenient. The second most important motivation is ecological - saving resources and using sustainable consumption. The significance of these motivations is greater than the average level for all motivations. It is interesting to note that at the value of slightly more than 20 , the curves of these motivations intersect, which indicates that there is a certain percentage of respondents for whom the ecological motivation is a priority over economic benefits. The third most important motivation is enjoyment from the process of sharing consumption. And the fourth, different from the others, the least significant is reputation - improving the image or gaining recognition among the members of one's community.

Since the ecological motive was the second most important for the respondents, it was necessary to understand how strongly sustainable development fits the value system of young active consumers, how it affects the attitude of consumers to the distributed use economy, and whether these values determine the behaviour and consumer choice of the young people.

\section{Sustainability values research}

For consumer decisions determined by the value system and based on them, it is advisable to use deliberative research methods, which allow not to be dependent on the subjective opinion of a researcher or expert, but to use the results of discussions with representatives of the target group of consumers $[7,8,10]$. The concept of deliberative democracy is one of the modern trends in the theory of democracy, formed in the $80 \mathrm{~s}$ of the XX century. Representatives of the deliberative approach moved from understanding democracy as a system of aggregation of conflicting opinions and preferences to considering it as a process of forming and transforming preferences, carried out through communication between informed and equal citizens [8]. In public life, deliberative methods are expressed in holding public hearings on important issues and in participatory budgeting [8]. Deliberative methods are also used in various studies on socially important issues in the form of deliberative seminars, focus groups, surveys, and consultations. The main rationale for deliberative research is to identify informed, balanced opinions of representatives of the 
target group, often on complex issues that they may not have previously paid much attention to.

A deliberative discussion on the importance of sustainable development values for young active consumers was held in two online sessions on the MS Teams platform in June 2020. The first session was attended by 23 students of the Russian university master program, and the second session was attended by 20 students from France, Finland, Austria, Slovakia, and India who were participating in the international exchange programs of the same university. To prepare the discussion, participants were provided with information materials on the distributed use economy: scientific articles in Russian and English with an overview of definitions, and the analysis of the preferences of users of sharing services; publications in the business press analysing Airbnb services and carsharing systems. The information materials were not specially edited and presented different points of view on distributed use economy, which fits the requirements for deliberative discussion sessions. Before the discussion, which was moderated by the authors of this paper, participants were explained the procedure and rules of discussion and invited to share their opinions about whether the use of sharing services is an example of responsible consumption, whether their use leads to a more sustainable economic development.

The participants of the sessions confirmed the results of the online survey, showing that sustainable development, the desire to save natural resources and stick to sustainable consumption was an important factor in shaping their attitude to the distributed use economy. The participants of the sessions gave examples of their own experience in using various sharing services and confirmed that they planned to use them more frequently in the future. All participants agreed that the ecological factor was an important motive for sharing. Even if the use of car sharing, for example, was driven by convenience ("you do not need to look for a parking space") or savings ("there is no money to buy a car, and taxis are too expensive"), ecological motives were still present and influenced the choice of consumers.

It is interesting that the feeling of pleasure and novelty from using sharing platforms, according to the participants of the discussion, quickly weakens out. This motive is relevant only at the beginning, during the first experience of sharing. With more experience in distributed use economy, the functions provided by the digital platforms were considered solely from the point of view of convenience.

The importance of the information provided to participants in the deliberative session should be noted: some participants mentioned that the information materials provided before the discussion were important to them, as they highlighted previously unknown aspects of distributed use, helped to form or even change the participants' opinions. Participants could change their position during and after the discussion, agreeing with the arguments of other members of the group. This concerned, for example, the priority of motives when using car sharing: participants concluded that ecological motives have a greater impact on the attitude of users than they imagined, even if the direct driver to use the service was an economic benefit. This confirms the results of the existing studies $[15,19]$.

Distributed use is seen as a mode of consumption preferred by environmentally conscious consumers. Our results also suggest that considering distributed use as an activity leading to sustainable development can influence the spread of positive attitudes and more active use of the sharing services. The results of the study show that at the beginning of using sharing services, the consumer can enjoy the feeling of novelty, mastering new technologies, which plays a significant role in shaping the attitude and intention to use such services. Some consumers participate in sharing simply because it is fun and provides a new way to interact with other members of the community. Gradually, new norms of behaviour are formed [14]. On the one hand, this reduces the sense of novelty and 
enjoyment from using sharing services, and on the other hand, it turns into a new motivator - following the norms of one's community. There may be a gradual replacement of internal motives for using sharing with external norms of behaviour.

\section{Conclusions}

Comparing the results of this research to data in other publications $[15,19,20]$ can show similar patterns of motives guiding consumers in using sharing economy. Sustainable development being an important factor in the formation of positive attitudes towards sharing, the economic benefits are a strong motivator for intentions to participate in the distributed use economy. Our results also support the idea that positioning sharing as a sustainable activity can result in an increase in frequency of its use. Our results, however, also showed that the positive attitude to sharing as a sustainable consumption pattern may not directly translate into a more intensive use of sharing, as consumers are using it mainly for economic benefits. It shows that some authors were right to believe that some consumers are demonstrating their altruistic attitude and share their assets, while others are just enjoying the benefits of sharing [15]. This may affect the sustainability of distributed use economy in general.

This research can have several implications for the providers of digital platforms and sharing services. The sharing should be easy and comfortable to use because enjoyment is an important motivator at the beginning. Sharing services providers should not underestimate the importance of ecological motives and should consider using the ideas of sustainable development in their communications with potential users.

Future research can consider measuring the frequency of use affected by different motives, preference of different motives by consumers of different age groups, and the motivation pattern differences for those who are providing the assets and those who get access to the assets through sharing.

Prepared in the framework of the state task of the Ministry of Science and Higher Education No. FSSW-2020-0009 "Developing a methodology for managing the competitiveness of enterprises in the field of commodity circulation in the digital economy".

\section{References}

1. F. Bardhi, G.W. Eckhardt, J. Consum. Res., 39(4), 881-898 (2012)

2. R. Belk, Ann. Am. Acad. Polit. Ss., 611(1), 126-140 (2007)

3. Y. Benkler, The Wealth of Networks: How Social Production Transforms Markets and Freedom (New Haven and London: Yale University Press, 528, 2006)

4. R. Botsman, FastCompany (2015) https://www.fastcompany.com/3046119/definingthe-sharing-economy-what-is-collaborative-consumption-and-what-isnt (Accessed on 18.07.2020)

5. R. Botsman, R. Rogers, Harvard Bus. Rev., 88(10), 30 (2010)

6. R. Botsman, R. Rogers, What's Mine Is Yours: The Rise of Collaborative Consumption (HarperBusiness, 280, 2010)

7. T. Burchardt, P. Vizard, J. Hum. Dev. Capab., 12 (1), 91-119 (2011)

8. T. Burchardt, Qual. Res. J., 14(3) (2012)

https://www.researchgate.net/publication/254397973_Deliberative_research_as_a_tool to_make_value_judgements/ 
9. D. Dredge, S. Gyimóthy, Tourism Recreation Research, 40(3), 286-302 (2015)

10. J. Fishkin, When the People Speak: deliberative democracy and public consultation (Oxford: Oxford University Press, 2009)

11. C. Fitzmaurice, J. Schor, Collaborating and Connecting: The Emergence of the Sharing Economy (ed. L. Reisch, J. Thogersen, Handbook of Research on Sustainable Consumption, Edgar Elgar, Massachusetts, 410-425, 2015)

12. K. Frenken, T. Meelen, M. Arets, P. van de Glind, The Guardian (2015) https://www.theguardian.com/science/political-science/2015/may/20/smarterregulation-for-the-sharing-economy (Accessed on 10.06.2020)

13. K. Frenken, J. Schor, Environ. Innovation Soc. Transitions, 23, 3-10 (2017) https://www.researchgate.net/publication/312598648_Putting_the_sharing_economy_i nto_perspective (Accessed on 12.06.2020).

14. G. Georgina, Management, University of Primorska, Faculty of Management Koper, 13(2), 175-189 (2018) Retrieved from: http://www.hippocampus.si/ISSN/18544231/13.175-189.pdf (Accessed on 10.06.2020)

15. J. Hamari, M. Sjöklint, A. Ukkonen, J. Assoc. Inf. Sci. Tech., 67 (9), 2047-59 (2015)

16. A. Johansson, P. Kisch, M. Mirata, J. Clean. Prod., 13(10-11), 971-979 (2005)

17. V. Kolmakov, Theoretical and applied economics, 1, 49 - 63 (in Russian) (2020)

18. T. Meelen, K. Frenken, Fast Company (2015) Retrieved from: http://www.fastcoexist.com/3040863/stop-saying-uber-is-partof-the-sharing-economy (Accessed on 18.07.2020)

19. M. Mareike, J. Consum. Behav., 14(3), 193-207 (2015)

20. H. Nijland, J. Van Meerkerk, A. Hoen, PBL Netherland Environmental Assessment Agency, 1842 (2015) Retrieved from: https://www.pbl.nl/en/publications/impact-ofcar-sharing-on-mobility-and-co2-emissions (Accessed on 19.07.2020)

21. M. Petrini, C.S. de Freitas, L.M. da Silveira, Revista de Administração Mackenzie, 18(5), 39-62 (2017) Retrieved from:

https://www.researchgate.net/publication/321152498_A_proposal_for_a_typology_of_shari ng_economy/ (Accessed on 22.08.2020)

22. PricewaterhouseCoopers, The Sharing Economy: Sizing the Revenue Opportunity (2015) Retrieved from:

http://www.pwc.co.uk/issues/megatrends/collisions/sharingeconomy/the-sharing-economysizing-the-revenue-opportunity.html (Accessed on 19.06.2020)

23. Q.M. Anglada, A.B. Hernández Lara, Economic Research-Ekonomska Istraživanja, 33(1), 2787-2805 (2019) Retrieved from:

https://www.tandfonline.com/doi/full/10.1080/1331677X.2019.1694427 (Accessed on 19.07.2020)

24. A. Rinne, What Exactly is the Sharing Economy? World Economic Forum, 13 December Retrieved from: https://www.weforum.org/agenda/2017/12/when-issharing-not-really-sharing/ (Accessed on 12.06.2020) (2017)

25. Y. Saginov, D. Zavyalov, O. Saginova, Russian Journal of Innovation Economics, 10(3), 1403-1424 (in Russian) (2020)

26. R. Sidorchuk, A. Meshkov, B. Musatov, I. Skorobogatykh, D. Efimova, J. Appl. Econ., 13(1), 150-163 (2018) 
27. V. Shved, V. Yablochnikov V. (2018) Specific features of sharing economy in Ukrain. Business. Education. Law. Bulletin of the Volgograd business institute -2 (43) - c. 75 80 (in Russian) (2018)

28. I.P. Tussyadiah, J. Pesonen, J. Travel Res., 55(8), 1-19 (2015)

29. N. Zavyalova, D. Zavyalov, Economy and Entrepreneurship, 1(102), 656-663 (in Russian) (2019) 